\title{
EDUCAÇÃO AMBIENTAL EM FOCO NO ENSINO BÁSICO
}

\author{
Rosangela Inês Matos Uhmann ${ }^{1}$ \\ Fernanda Seidel Vorpagel ${ }^{2}$
}

\begin{abstract}
Resumo
Esta pesquisa se refere ao estudo das estratégias de ensino (EE) que permeiam a educação ambiental (EA) na educação básica (EB). A EA é um tema transversal que precisa de atenção em meio educacional, visto que o trabalho pedagógico desenvolvido na escola deve proporcionar ações e atitudes que insiram o educando na abrangência da complexidade crítica da EA. Para tanto, investigamos o tema por meio de uma revisão bibliográfica em periódicos e de um questionário endereçado a professores da EB sobre quais e como são efetivadas as EE de EA. A partir deste estudo foram depreendidas as categorias práticas de EA em periódicos e a EA no contexto da EB, o que evidenciou a falta de sistematização das práticas desenvolvidas na EB, o que pode ser melhorado, contudo, com a inserção de um trabalho coletivo em meio escolar com práticas contínuas de EA.
\end{abstract}

Palavras-chaves: Práticas Ambientais. Escola Básica. Estratégias de Ensino.

\section{ENVIRONMENTAL EDUCATION IN FOCUS IN BASIC EDUCATION}

\begin{abstract}
This study refers to the study of teaching strategies (TS) that permeate environmental education (EE) in basic education (BE). EE is a cross-cutting theme that needs attention in education, as the pedagogical work developed in school must provide actions and attitudes that insure the student's comprehension of the critical complexity of EE. Thus, we investigated this subject through a bibliographic review in a periodical and a questionnaire made to BE teachers about which and how TS and EE are performed. The categories EE practices in periodic and $\mathrm{EE}$ in the context of $\mathrm{BE}$ emerged from the study, which evidenced the lack of systematization of the practices developed in BE. However it can be improved by inserting a collective work in school in the direction of continuous EE practices.
\end{abstract}

Keywords: Environmental practices. Basic School. Teaching Strategies.

\section{EDUCACIÓN AMBIENTAL EN EL FOCO DE LA ENSEÑANZA BÁSICA}

\section{Resumen}

Esta investigación se refiere al estudio de las estrategias de enseñanza (EE) en relación con la educación ambiental (EA) en la educación básica (EB). La EA es un tema transversal que requiere atención en el medio educativo, ya que el trabajo pedagógico desarrollado en la escuela necesita proporcionar acciones y actitudes que posibilitan al educando alcanzar la complejidad crítica de la EA. Para ello, por medio de una revisión bibliográfica en periódicos

\footnotetext{
${ }^{1}$ Doutorado e Mestrado em Educação nas Ciências pela Unijui. Coordenadora do PIBID. Membro do GEPECIEM. Vice-coordenadora do Programa de Pós-Graduação em Ensino de Ciências. Professora dos Curso de Química Licenciatura da Universidade Federal da Fronteira Sul (UFFS), Campus Cerro Largo, RS. E-mail: rosangela.uhmann@uffs.edu.br

${ }^{2}$ Licenciada em Química pela UFFS, Campus Cerro Largo. Bolsista de Iniciação Científica da Fundação de Amparo à Pesquisa do Estado do Rio Grande do Sul (FAPERGS).

E-mail: vorpagelfernanda@gmail.com
} 
y en cuestionarios aplicados a profesores de la EB, investigamos sobre cuáles y cómo se efectúan las EE en la EA. A partir del estudio, surgieron las categorías: prácticas de EA en periódico y EA en el contexto de la EB, lo que evidenció la falta de sistematización de las prácticas desarrolladas en la EB, pero que puede mejorarse con la inserción de un trabajo colectivo en el medio escolar con prácticas continuas de EA.

Palabras clave: Prácticas medioambientales. Enseñanza Básica. Estrategias de Enseñanza.

\section{Considerações iniciais}

A educação ambiental (EA) é um tema transversal fundamental na sensibilização para a tomada de consciência, essa que precisamos adquirir e melhorar a fim de construirmos uma sociedade sustentável, considerando que a crise ambiental decorre principalmente dos meios e dos modos de produção do sistema capitalista.

Entendemos que a partir do processo educativo podemos criar condições de entendimento sobre as questões socioambientais. Nesse sentido, compreendemos a necessidade de estudar as estratégias de ensino (EE) com foco na EA, com relação à sistematização de suas práticas, em especial das que perpassam pelas aulas na educação básica (EB), por serem fundamentais para a construção da EA crítica e globalizada.

No que diz respeito à sistematização das práticas, tomamos a concepção de Holliday (2006) para entender esse processo, o qual permite produzir um novo conhecimento, a partir de um primeiro nível de conceitualização da prática concreta, possibilitando sua compreensão e induzindo a uma transcendência. Trata-se de compartilhar criticamente os resultados que surgem da interpretação dos estudos e de colocar sobre o tapete da reflexão coletiva as contribuições e os ensinamentos que se aprendem a partir do que foi vivido em particular.

Trabalhar na perspectiva da EA crítica ainda é um desafio, tendo em vista a complexidade das diferentes concepções e práticas existentes (também limitadas na sua efetivação). Com isso evidenciamos a necessidade de ampliar a questão da EA, principalmente no que diz respeito à sistematização das EE com foco na EA. Conforme Loureiro (2006, p. 63), "independentemente da perspectiva adotada, informar, conhecer, organizar e agir no cotidiano passam a se constituir como etapas do fazer educativo, e não educação em si isoladamente".

Com a pretensão de levantar dados sobre a EA, fomos à busca de informações, de modo que tais dados foram devidamente analisados para a contextualização da temática, recorrente a partir de uma revisão bibliográfica da Revista Eletrônica do Mestrado em Educação Ambiental (Remea), bem como de um questionário feito a oito professores supervisores do Programa Institucional de Bolsas de Iniciação à Docência (Pibid).

Na sequência, apresentamos o caminho da pesquisa, ou seja, a metodologia acerca do contexto das relações estabelecidas para este estudo. Posteriormente apresentamos as categorias elencadas, a saber: práticas de EA em edições da Remea (período de 2010 a 2012) e a $E A$ no contexto da $E B$, identificando as atividades e as sistematizações propostas na EB.

\section{O caminho da pesquisa}

Este estudo é referente a uma pesquisa qualitativa (LÜDKE; ANDRÉ, 2013) decorrente de inquietações a respeito das EE com foco na EA. Para tanto, realizamos uma revisão bibliográfica na Remea, observando o descritor EA nas palavras-chave e nos títulos dos artigos publicados no período de 2010 a 2012, sendo encontrados 147 publicações relevantes, do total de 189 artigos. Segundo o critério de análise, optamos pela leitura na 
íntegra dos 147 artigos (mesmo que a ideia inicial fosse optar pela leitura dos resumos), no sentido de observarmos as EE de EA adotadas por professores da EB, tendo em vista que os resumos, por vezes, não apresentam o contexto do trabalho realizado em sua totalidade. A partir da leitura identificamos as seis temáticas (Quadro 1). Entre estas, destacou-se a temática práticas de EA na EB (compreendendo 24 artigos), que será analisada por ter sido eleita temática desta pesquisa.

Quadro 1 - Organização de temáticas de educação ambiental na observação dos artigos da Remea (2010-2012).

\begin{tabular}{|c|c|c|}
\hline Temática & $\begin{array}{l}\text { Artigo } \\
\text { s }\end{array}$ & Citação retirada de um dos artigos encontrados \\
\hline $\begin{array}{l}\text { Práticas de } \\
\text { educação } \\
\text { ambiental } \\
\text { na educação } \\
\text { básica }\end{array}$ & 24 & $\begin{array}{l}\text { "Uma maneira interessante e importante para o desenvolvimento da } \\
\text { EA na escola pode ser no envolvimento dos estudantes nos } \\
\text { percursos em trilhas" (METTE; SILVA; TOMIO, 2010, p. 114). }\end{array}$ \\
\hline $\begin{array}{l}\text { Análise da } \\
\text { educação } \\
\text { ambiental } \\
\text { em contexto } \\
\text { escolar }\end{array}$ & 22 & $\begin{array}{l}\text { "Este estudo tem por objetivo detectar se as práticas pedagógicas no } \\
\text { ensino fundamental do Centro Educacional Professor Paulo Freire } \\
\text { (CAIC), em Vitória da Conquista - BA, são ambientalistas e } \\
\text { comunicativas, bem como identificar as concepções dos alunos a } \\
\text { respeito de educação ambiental e meio ambiente" (SILVA; } \\
\text { JÚNIOR, 2012, p. 1). }\end{array}$ \\
\hline $\begin{array}{l}\text { Educação } \\
\text { ambiental e } \\
\text { formação } \\
\text { docente }\end{array}$ & 19 & $\begin{array}{l}\text { "Frente a esse mundo efêmero pensamos ser necessário criar } \\
\text { algumas rupturas nas maneiras de atuar e ser professor, pois a escola } \\
\text { já não dá conta das questões da contemporaneidade" (ALBERNAZ; } \\
\text { LAURINO, 2011, p. } 38 \text { ). }\end{array}$ \\
\hline $\begin{array}{l}\text { Educação } \\
\text { ambiental } \\
\text { não formal }\end{array}$ & 29 & $\begin{array}{l}\text { "Um grande desafio a ser superado, haja vista que comumente a } \\
\text { população que compõe a terceira idade não constitui alvo de } \\
\text { projetos voltados à questão ambiental" (DUARTE; GUIMARÃES; } \\
\text { SILVA, 2010, p. 135). }\end{array}$ \\
\hline $\begin{array}{l}\text { Como a } \\
\text { mídia } \\
\text { perpassa } \\
\text { pela } \\
\text { educação } \\
\text { ambiental }\end{array}$ & 4 & $\begin{array}{l}\text { "Utilizando as ferramentas conceituais de Biopoder e Sociedade de } \\
\text { Controle evidencia-se o quanto os discursos da Educação Ambiental } \\
\text { presentes na mídia são uma importante estratégia de controle social } \\
\text { na atualidade" (HENNING, C.; GARRÉ; HENNING, P., 2010, p. } \\
\text { 243). }\end{array}$ \\
\hline $\begin{array}{l}\text { Concepções } \\
\text { teóricas } \\
\text { acerca da } \\
\text { educação } \\
\text { ambiental }\end{array}$ & 49 & $\begin{array}{l}\text { "A possibilidade da educação ambiental passa pela oportunidade de } \\
\text { vivenciar imaginários não centrados no ser humano, mas que o } \\
\text { incluam, restaurando a face da sensibilidade solidária para com a } \\
\text { natureza e a vida nas suas mais diversas formas e manifestações } \\
\text { (STRIEDER, 2012, p. 189). }\end{array}$ \\
\hline
\end{tabular}

Fonte: elaboração dos autores (2017). 
O Quadro 1 apresenta as temáticas relacionadas à EA com base na observação da Remea, em que as práticas de EA na EB desenvolvidas pelos professores referem-se às EE, ou seja, às atividades desenvolvidas no âmbito da EB, compreendendo a educação infantil, o ensino fundamental e médio. A temática análise da EA em contexto escolar diz respeito a contribuições e inferências realizadas pelos autores dos artigos a partir de uma atividade ou um fato transcorrido na escola. O tema EA e formação docente compreende artigos que tratam da formação de professores na perspectiva da EA.

Por sua vez, a EA não formal abrange os artigos que tratam de atividades da EA desenvolvidas por organizações não governamentais (ONG), grupos de terceira idade, asilos, igrejas e estabelecimentos privados. Já a temática como a mídia perpassa pela EA articula a influência da mídia nas questões socioambientais. Por fim, a temática concepções teóricas acerca da EA contempla artigos que se voltam a discussões filosóficas, epistemológicas e de pesquisa bibliográfica, bem como de outros temas variados. Ainda com vistas a aprofundar a temática de práticas de $\mathrm{EA}$ na $\mathrm{EB}$, fizemos um questionário para oito professores que atuam na EB.

Para preservar a identidade dos respondentes, todos foram nomeados como P1, P2, e assim sucessivamente, o que segue os preceitos éticos da pesquisa com seres humanos, conforme a submissão ao Comitê de Ética. Coletou-se também a assinatura do Termo de Consentimento Livre e Esclarecido (TCLE). O projeto de pesquisa foi aceito sob o parecer $\mathrm{n}^{\circ}$ 2.105.800 (CAAE: 68193817.9.0000.5564). Quanto à análise dos dados, a revisão bibliográfica da Remea e a realização do questionário remontam à análise de conteúdo com base em Bardin (1995), que pressupõe, na primeira etapa, a pré-análise; na segunda, a inferência; e por fim a interpretação. $\mathrm{Na}$ sequência abordamos, por meio de revisão bibliográfica, aspectos das práticas de EA.

\section{Práticas de educação ambiental em edições da Remea}

A decisão de fazer uma revisão bibliográfica na Remea deve-se à ampla circulação da revista e ao fato de ser referência em artigos de EA. Em tal periódico foram encontrados 147 artigos, entre 2010 e 2012 (conforme consta na metodologia), tendo sido observadas as EE realizadas por professores da EB. Essas EE desenvolvidas como atividades de ensino com foco na EA necessitam ser compreendidas a fim de se observar se a EA está sendo sistematizada, bem como se as atividades são pontuais e/ou levam em conta as relações intrínsecas do processo de ensinar e aprender.

No estudo dos 24 artigos constitutivos da temática que compreende as práticas de EA na $E B$ (dentre as seis temáticas apresentadas no Quadro 1), evidenciamos diversas formas de sistematizar as atividades realizadas, das quais destacamos a escrita (Quadro 2), o desenho (Quadro 3), maquetes, tabulação de dados, questionário e entrevista; bem como a falta de instrumento de sistematização da prática e a importância da prática de EA de forma sistemática (Quadro 4).

Ao buscarmos fundamentação sobre a sistematização da prática, nos ancoramos nas ideias de Holliday (2006) nas quais se destaca a sistematização como um caminho difícil e pouco transitado, compreendendo o intermediário entre a descrição de uma experiência e a reflexão teórica. A sistematização é o primeiro nível de conceitualização e pode contribuir no sentido de melhorar a experiência, às vezes no enriquecimento da teoria.

Compreendemos que a sistematização possibilita a análise crítica dos aspectos que permeiam o processo da EA, por exemplo, fazendo com que as ações sejam significativas e de responsabilidade entre os sujeitos escolares. Nesse sentido, é necessário discutir a falta, pois, sem sistematização, as práticas desenvolvidas ficam muitas vezes no fazer pelo fazer. 
De acordo com Holliday (2006), a sistematização da prática deve ser feita de modo contínuo e recorrente, caso contrário ela perde seu sentido transformador, que é o de gerar aprendizagem sobre nossas ações. Por isso a sistematização não pode se dar de forma pontual e isolada. Entendemos que as ações de EA geralmente não atingem o público global, pois são pontuais e específicas de um contexto - o que não desmerece a prática. Porém, ainda que a atividade seja local, o pensamento precisa ser holístico, a fim de compreender a criticidade das questões ambientais.

Com essa visão, contemplamos o objetivo da atividade, o conteúdo envolvido, as EE, o contexto, bem como a sistematização da prática de EA descritos nos artigos analisados, evidenciados no Quadro 2.

Quadro 2 - A escrita como sistematização da prática de educação ambiental.

\begin{tabular}{|c|c|c|c|c|c|}
\hline Autores & Objetivo & Conteúdo & $\begin{array}{l}\text { Estratégias } \\
\text { de ensino } \\
\text { com foco na } \\
\text { educação } \\
\text { ambiental }\end{array}$ & $\begin{array}{l}\text { Contexto da } \\
\text { prática de } \\
\text { educação } \\
\text { ambiental }\end{array}$ & $\begin{array}{l}\text { Sistematizaçãa } \\
\text { o da prática } \\
\text { de educação } \\
\text { ambiental }\end{array}$ \\
\hline $\begin{array}{l}\text { ALMEIDA, } \\
\text { M. L.; } \\
\text { FETTER, } \\
\text { R.; } \\
\text { GERMAN } \\
\text { O, E. }\end{array}$ & $\begin{array}{l}\text { Avaliar o } \\
\text { Projeto de } \\
\text { Conservação } \\
\text { e Utilização } \\
\text { Sustentável } \\
\text { da } \\
\text { Diversidade } \\
\text { Biológica } \\
\text { Brasileira. }\end{array}$ & $\begin{array}{l}\text { Biomas } \\
\text { brasileiros. }\end{array}$ & $\begin{array}{ll}\text { Leitura } & \\
\text { orientada } & \mathrm{e} \\
\text { roda } & \text { de } \\
\text { conversa. } & \end{array}$ & $\begin{array}{l}\text { Coletivo } \\
\text { escolar. }\end{array}$ & Escrita. \\
\hline $\begin{array}{l}\text { PEINADO, } \\
\text { S. do V.; } \\
\text { RECENA, } \\
\text { M. C. P. }\end{array}$ & $\begin{array}{l}\text { Descrever o } \\
\text { desenvolvime } \\
\text { nto de uma } \\
\text { sequência } \\
\text { didática para } \\
\text { inserção da } \\
\text { educação } \\
\text { ambiental nas } \\
\text { séries inicias. }\end{array}$ & $\begin{array}{l}\text { Rio Paraguai } \\
\text { e peixe Pacu. }\end{array}$ & $\begin{array}{lr}\text { Estudo } & \text { do } \\
\text { livro } & \text { com } \\
\text { entrevista } & \text { a } \\
\text { autora, } & \\
\text { leitura } & \text { de } \\
\text { textos, } & \\
\text { música, } & \\
\text { visita } & \text { e } \\
\text { jogos. } & \\
\end{array}$ & $\begin{array}{l}\text { Coletivo } \\
\text { escolar. }\end{array}$ & $\begin{array}{l}\text { Escrita (diário } \\
\text { de bordo). }\end{array}$ \\
\hline $\begin{array}{l}\text { UHMANN, } \\
\text { R. I. M.; } \\
\text { ZANON, L. } \\
\text { B. }\end{array}$ & $\begin{array}{l}\text { Apresentar os } \\
\text { resultados de } \\
\text { uma pesquisa } \\
\text { qualitativa } \\
\text { com vistas a } \\
\text { compreender } \\
\text { estratégias de } \\
\text { ensino e } \\
\text { interações em } \\
\text { aulas. }\end{array}$ & $\begin{array}{l}\text { Composição } \\
\text { das pilhas, } \\
\text { eletrodinâmic } \\
\text { a e } \\
\text { eletrostática. }\end{array}$ & $\begin{array}{l}\text { Discussão e } \\
\text { interação } \\
\text { com a } \\
\text { comunidade. }\end{array}$ & $\begin{array}{l}\text { Coletivo } \\
\text { escolar do } 3^{\circ} \\
\text { ano do } \\
\text { ensino médio } \\
\text { e } \\
\text { comunidade. }\end{array}$ & Escrita. \\
\hline
\end{tabular}




\begin{tabular}{|c|c|c|c|c|c|}
\hline $\begin{array}{l}\text { BRUSSE, } \\
\text { F. P. L.; } \\
\text { BARBOSA } \\
\text { VEIGA, R. } \\
\text { F. A. }\end{array}$ & $\begin{array}{lr}\text { Descrever } & \text { um } \\
\text { modelo } & \text { de } \\
\text { projeto } & \text { com } \\
\text { foco } & \text { na } \\
\text { educação } & \\
\text { ambiental } & \\
\text { agrícola. } & \end{array}$ & $\begin{array}{l}\text { Produção } \\
\text { agrícola } \\
\text { sustentável e } \\
\text { sistemas de } \\
\text { plantio. }\end{array}$ & $\begin{array}{l}\text { Aula teórica, } \\
\text { prática } \\
\text { saída } \\
\text { campo. }\end{array}$ & $\begin{array}{l}\text { Coletivo } \\
\text { escolar em } \\
\text { três escolas. }\end{array}$ & Escrita. \\
\hline $\begin{array}{l}\text { FUERTAD } \\
\text { O, I. O.; } \\
\text { PINTO, C. } \\
\text { L. L. } \\
\text { CALIXTO, } \\
\text { P. M. }\end{array}$ & $\begin{array}{l}\text { Conhecer o } \\
\text { uso da } \\
\text { fotografia e } \\
\text { repercussões } \\
\text { no processo } \\
\text { de ensino e } \\
\text { aprendizagem } \\
\text {. }\end{array}$ & $\begin{array}{l}\text { Geografia } \\
\text { urbana. }\end{array}$ & $\begin{array}{l}\text { Registro de } \\
\text { fotos. }\end{array}$ & $\begin{array}{l}\text { Coletivo } \\
\text { escolar do } 2^{\circ} \\
\text { ano } \\
\text { ensino } \\
\text { médio. }\end{array}$ & $\begin{array}{l}\text { Escrita } \\
\text { coletiva. }\end{array}$ \\
\hline
\end{tabular}

Fonte: elaboração dos autores (2017).

Dos 24 artigos analisados, cinco apresentam, na sistematização da prática de EA, a escrita. A escrita é uma ferramenta muito importante no processo de ensino e aprendizagem, bem como na validação da fundamentação da prática realizada, pois através da escrita as minúcias dos aspectos relacionados ao processo da experiência se tornam evidentes.

Escrever nos faz pensar, e esse movimento articula questionamentos concisos para práticas ambientais mais críticas. Urge, assim, a indagação de por que a prática de EA, por exemplo, foi realizada desta e não de outra maneira, qual foi o objetivo almejado, bem como se foi atingida a atividade específica local, mas com pensamento global.

A importância da escrita no processo e nas transformações que ela provoca nos sujeitos é estudada por Wenzel (2014), que compreende o escrever como situação-problema em que o autor revisa seus textos e descobre novas relações, transformando seu pensamento nesse processo. Entendemos que a escrita é uma EE importante para provocar mudanças no cenário da EA, pois possibilita tomada de consciência nas ações desenvolvidas.

A EE por meio do desenho também foi evidenciada como forma de sistematizar a prática com foco na EA abordada no Quadro 3, compreendendo o contexto das práticas desenvolvidas.

Quadro 3 - O desenho como sistematização da EA.

\begin{tabular}{|c|c|c|c|c|c|}
\hline Autores & Objetivo & Conteúdo & $\begin{array}{l}\text { Estratégias } \\
\text { de ensino } \\
\text { com foco na } \\
\text { educação } \\
\text { ambiental }\end{array}$ & $\begin{array}{l}\text { Contexto da } \\
\text { prática de } \\
\text { educação } \\
\text { ambiental }\end{array}$ & $\begin{array}{l}\text { Sistematizaç } \\
\text { ão da prática } \\
\text { de educação } \\
\text { ambiental }\end{array}$ \\
\hline $\begin{array}{l}\text { METTE, G.; } \\
\text { SILVA, J. C. } \\
\text { D.; TOMIO, } \\
\text { D. }\end{array}$ & $\begin{array}{l}\text { Avaliar e } \\
\text { ampliar a } \\
\text { percepção de } \\
\text { estudantes } \\
\text { sobre o meio } \\
\text { ambiente }\end{array}$ & $\begin{array}{l}\text { Percepção de } \\
\text { educação } \\
\text { ambiental. }\end{array}$ & $\begin{array}{l}\text { Desenho } \\
\text { diagnóstico, } \\
\text { palestra } \\
\text { trilha. }\end{array}$ & $\begin{array}{l}\text { Coletivo do } \\
5^{\circ} \text { ano. }\end{array}$ & Desenho. \\
\hline
\end{tabular}




\begin{tabular}{|l|l|l|l|l|l|}
\hline & $\begin{array}{l}\text { com base nos } \\
\text { Parâmetros } \\
\text { Curriculares } \\
\text { Nacionais. }\end{array}$ & & & \\
\hline $\begin{array}{l}\text { CORREIA, } \\
\text { C. J. S.; } \\
\text { ALMEIDA, } \\
\text { M. B. S.; } \\
\text { SILVA, M. } \begin{array}{l}\text { Discutir } \\
\text { percepções } \\
\text { ambientais de } \\
\text { jovens } \\
\text { afetados } \\
\text { pelas al al. } \\
\text { enchentes. }\end{array}\end{array}$ & Enchentes. & $\begin{array}{l}\text { Texto, vídeo, } \\
\text { reflexão e } \\
\text { discussão. }\end{array}$ & $\begin{array}{l}\text { Coletivo } \\
\text { escolar de 19 } \\
\text { escolas } \\
\text { municipais. }\end{array}$ & Desenho. \\
\hline $\begin{array}{l}\text { MARIA, E. } \\
\text { C.; ZANON, } \\
\text { A. M. }\end{array}$ & $\begin{array}{l}\text { Restaurar a } \\
\text { integridade } \\
\text { ecológica de } \\
\text { uma área de } \\
\text { preservação } \\
\text { permanente. }\end{array}$ & $\begin{array}{l}\text { Sucessão } \\
\text { ecológica. }\end{array}$ & $\begin{array}{l}\text { Horta e jogo } \\
\text { didático. }\end{array}$ & $\begin{array}{l}\text { Coletivo } \\
\text { escolar. }\end{array}$ & Desenho. \\
& & & \\
\end{tabular}

Fonte: elaboração dos autores (2017).

Evidenciamos em três artigos o desenho como EE na sistematização das práticas respectivas à EA. Destacamos que, no processo de desenvolvimento das práticas ambientais, as EE integraram diferentes ações pedagógicas, por meio de palestra, trilha, jogo didático e horta escolar. Foi nesse contexto que o desenho se constituiu como ferramenta de estudo das percepções acerca das questões ambientais. De acordo com Goldberg, Yunes e Freitas (2005), o desenho é um importante meio de comunicação e representação da criança, apresentando-se como atividade fundamental, pois a partir dele a criança expressa e reflete suas ideias, sentimentos e percepções. Compreendemos o desenho como uma das ferramentas didáticas e lúdicas do processo de ensino e aprendizagem.

Outras formas de sistematização foram encontradas em cinco artigos do periódico Remea, relativos a construção de maquetes, tabulação de dados, questionário e entrevista, constituindo diferentes formas de sistematizar as práticas de EA. Tais EE podem estar acompanhadas de uma reflexão teórica e crítica do processo no qual se desenvolveu a prática de EA, sendo consideradas, assim, como estratégias de sistematização. Compreendemos que a escolha da estratégia se dá pelo contexto específico de cada realidade, pois o que se aplica em um determinado local pode não ser aplicável em outro.

Por mais atualizado que seja um documento de referência, é fundamental que os protagonistas da EA tragam um olhar crítico ao adotar esse instrumento, no sentido de selecionar as informações que serão mais apropriadas ao seu trabalho e adaptáveis a sua realidade educacional, e não tentar reproduzi-las como instruções de um manual. (AGUIAR; FARIAS, 2017, p. 13).

A construção de maquetes, atrelada à reflexão como maneira de sistematização evidenciada, compreende o entendimento da percepção que crianças têm do lugar em que vivem. De acordo com Freire (1996), ensinar exige respeito aos saberes dos educandos, sendo importante, nesse processo, discutir em sala de aula a razão de ser de alguns desses saberes em relação ao ensino dos conteúdos - sobre a poluição de riachos com precária fiscalização, 
por exemplo. A tabulação de dados, o questionário e a entrevista, se bem utilizados e explorados na coleta de informações, permitem compreender o contex to em questão.

Além das diferentes formas de sistematização das práticas de EA, também evidenciamos a falta de sistematização das EE desenvolvidas com foco na EA. Cabe destacar que a falta é apontada como uma das limitações da EA. Evidenciamos em 10 dos 24 artigos a ausência de apresentação de uma sistematização da prática de EA como EE, o que não quer dizer que esta não possa ter sido sistematizada pelos sujeitos escolares; porém, nos artigos da Remea analisados, não foi possível evidenciá-la explicitamente. De acordo com Marques (2002), o conceito de sistematização incorpora a visão de continuidade, em que os conteúdos curriculares se organizam de modo contínuo, articulando outros mais complexos em relação às mudanças havidas e às relações percebidas.

Nesse sentido, é possível que estejamos vivendo em um cenário permeado pela globalização desenfreada, no qual compreender o sentido das ações pedagógicas através de conceitos construídos e não acabados pode consistir no movimento de produzir mudanças significativas em cada ambiente local (UHMANN, 2013). Destarte, a sistematização se constitui como ferramenta que vai além de justificar uma prática realizada, conduzindo também ao entendimento crítico da prática, com vistas a atingir maior nível de compreensão quanto às questões socioambientais.

Nessa direção, a ausência de sistematização acerca das práticas desenvolvidas com foco na EA esvazia-as do significado proposto, não avançando no entendimento do que se está fazendo e, por isso, limita um nível de compreensão que leve em conta os aspectos globais e possivelmente transformadores dos locais do dia a dia (e, por conseguinte, da sala de aula). "Só uma visão crítica da própria aula poderá mostrar os limites da ação pedagógica para avançar na aprendizagem profissional quando cada aula é motivo para aprender a aprender" (UHMANN, 2013, p. 166).

Entendemos a sistematização como uma ajuda para "descobrir formas e metodologias de trabalho de pesquisa e de EA nas quais a reflexão sobre as questões ecológicas estejam intrinsecamente relacionadas com os conteúdos curriculares das diferentes disciplinas, áreas e/ou níveis do processo educativo escolar" (BARCELOS, 2005, p. 81). Desse modo, a sistematização favorece a geração de ações que possibilitam a sensibilização sobre os cuidados ambientais na sociedade, que assim podem contribuir para uma vida saudável; do contrário, não se avança na viabilização das mudanças. Em contrapartida, apresentamos o Quadro 4, que consiste na sistematização permanente das EE com foco na EA.

Quadro 4 - Sistematização da prática de educação ambiental.

\begin{tabular}{|l|l|l|l|l|l|}
\hline Autores & Objetivo & Conteúdo & $\begin{array}{l}\text { Estratégias } \\
\text { de ensino } \\
\text { com foco na } \\
\text { educação } \\
\text { ambiental }\end{array}$ & $\begin{array}{l}\text { Contexto prática } \\
\text { da } \\
\text { de } \\
\text { educação } \\
\text { ambiental }\end{array}$ & $\begin{array}{l}\text { Sistematização } \\
\text { da prática } \\
\text { educação } \\
\text { ambiental }\end{array}$ \\
\hline $\begin{array}{l}\text { ARAÚJO, } \\
\text { A.; } \\
\text { RIBEIRO, } \\
\text { I. M. P. }\end{array}$ & $\begin{array}{l}\text { Implementar a } \\
\text { Agenda } \\
\text { Ambiental } \\
\text { (resolver } \\
\text { problemas } \\
\text { específicos da } \\
\text { escola). }\end{array}$ & $\begin{array}{l}\text { Educação } \\
\text { ambiental } \\
\text { e lixo. }\end{array}$ & Projeto. & $\begin{array}{l}\text { Coletivo } \\
\text { escolar. }\end{array}$ & $\begin{array}{l}\text { Estratégia de } \\
\text { sistematização } \\
\text { contínua. }\end{array}$ \\
\hline
\end{tabular}

Fonte: elaboração dos autores (2017). 
Precisamos considerar todos os aspectos do processo de desenvolvimento das práticas de EA, por exemplo, no sentido de realizar a tomada de consciência das ações desenvolvidas de forma contínua e sistemática. Esse movimento permite a transformação e a geração de conhecimentos, com vistas a articular no tempo presente as ações de cuidado para um futuro habitável. De acordo com Loureiro (2006), pensar de forma complexa implica uma ação consciente, no sentido de se saber o alcance de determinada ação, apresentando coerência entre o que se quer, o conhecimento dos sujeitos, a base teórica da qual se parte, aonde se quer chegar e quem se beneficia com o processo desenvolvido.

Nesse sentido, para compreendermos possíveis sistematizações realizadas na prática e o modo como acontecem, passamos a discorrer sobre elas a partir das contribuições de algumas professoras participantes desta pesquisa. De antemão, destacamos a importância da sistematização da EA para possibilitar a reorientação da prática, a fim de que esta seja significativa frente às mudanças exigidas na contemporaneidade, o que nos fez questionar a especificidade das práticas de EA desenvolvidas por alguns professores, em destaque a seguir.

\section{Educação ambiental no contexto da educação básica}

Ao pensarmos nas práticas de EA observadas nos artigos publicados na Remea, emergiu a ideia de explorar a EA no contexto da EB (por meio de questionários dirigidos a professores) no sentido de entender a ausência de sistematização das ações de EA evidenciada em dez dos artigos avaliados. Isso requer considerarmos com ênfase o contexto escolar, desde as séries iniciais até o ensino superior, visto que tais espaços são propulsores do processo de ensino e aprendizagem. Assim, este estudo com relação às EE com foco na EA ajuda na publicização de informações, considerando a difusão de discussões sobre a temática ambiental na contemporaneidade.

Acreditamos que o espaço de formação (inicial e continuada) próprio das licenciaturas, com foco em temas emergentes, a exemplo da EA, faz diferença na constituição de sujeitos críticos em relação à realidade, graças à possibilidade de trocas de vivências entre professores e licenciandos. Compreender, verificar, inferir e estudar como são desenvolvidas e sistematizadas as atividades de EA realizadas por professores da EB é considerar o processo de ensino em contextos diversificados de formação.

Em se tratando das sistematizações planejadas nas EE com foco na EA, urge que se estabeleça um intercâmbio de vivência, em diferentes contextos, para gerar discussões decorrentes da problematização enquanto eixo integrador. Ao tratarmos a EA como tema transversal, compreendemos que nós, professores, precisamos trabalhar questões voltadas ao meio ambiente em sala de aula no decorrer do ano letivo. Assim, é de fundamental "importância o papel dos professores e dos outros adultos como modelos no desenvolvimento da alfabetização ambiental” (STERN; POWWER; HILL, 2014, p. 9, tradução nossa). A inquietação existe no sentido de entender como as práticas estão sendo realizadas e sistematizadas, visto que "a EA promove a conscientização e esta se dá na relação entre o 'eu' e o 'outro' pela prática social reflexiva e fundamentada teoricamente” (LOUREIRO, 2006, p. 29).

Tomando como base as ideias de Loureiro (2006) sobre a prática reflexiva, em especial sobre a EA, aproveitamos para trazer algumas das perguntas dos questionários (Quadro 5) respondidos por sete professoras (das oito que o receberam). 
Quadro 5 - Perguntas sobre a educação ambiental.

\begin{tabular}{|l|l|}
\hline Perguntas & $\begin{array}{l}\text { Professoras } \\
\text { responderam }\end{array}$ \\
\hline $\begin{array}{l}\text { 4) Como você compreende a importância da educação } \\
\text { ambiental? }\end{array}$ & P3 e P6. \\
\hline $\begin{array}{l}\text { 7) Quais as estratégias de ensino desenvolvidas de educação } \\
\text { ambiental em contexto escolar? }\end{array}$ & $\begin{array}{l}\text { P1, P2, P3, P4, P5, P6 e } \\
\text { P7. }\end{array}$ \\
\hline $\begin{array}{l}\text { 8) No contexto das aulas quais estratégias de ensino estão } \\
\text { voltadas para a questão ambiental anualmente? }\end{array}$ & P1, P2, P6 e P7. \\
\hline $\begin{array}{l}\text { 10) Como são sistematizadas (avaliadas) as práticas de } \\
\text { educação ambiental [...]? }\end{array}$ & P1, P2 e P7. \\
\hline $\begin{array}{l}\text { 11) Quais as dificuldades encontradas para trabalhar com a } \\
\text { educação ambiental em sala de aula? }\end{array}$ & P1, P2 e P3. \\
\hline
\end{tabular}

Fonte: elaboração dos autores (2017).

Quanto à pergunta 4, de modo geral, as professoras destacaram a importância da EA, direcionando-se para diferentes aspectos no que diz respeito à preservação do meio ambiente. No entendimento de P3, a EA é "muito importante, pois estamos neste mundo e não somos eternos". P6 avança: "Eu considero a EA importante, pois ela busca ações educativas que possam levar o ser humano a gerar uma consciência ecológica e assim se preocupar com suas atitudes e as atitudes coletivas, necessárias para o desenvolvimento de uma sociedade".

É oportuno o desenvolvimento de atitudes de forma integrada em contexto escolar, em que as concepções discutidas, de certa forma, vão influenciando as práticas voltadas para o cuidado ambiental. Pensar como P6 diz respeito à questão da sensibilização com as questões ambientais, as quais estão "diretamente vinculadas aos problemas sociais que afetam o cidadão, os quais exigem um posicionamento quanto ao encaminhamento de soluções" (SANTOS; SCHNETZLER, 2013, p. 47).

Leff (2006) aponta que praticamente todo mundo tem consciência dos problemas ecológicos que afetam a qualidade de vida, no entanto, suas ações são fragmentadas e pontuais, e nem todas as formas de consciência ocasionam movimentos sociais. Muitas vezes os problemas são entendidos a partir de concepções diferenciadas: no caso do aquecimento global, por exemplo, existem compreensões que dizem respeito tanto às catástrofes naturais quanto ao efeito da racionalidade ambiental (diálogo de saberes). Dias (2000) alerta para as consequências das ações antrópicas dos seres humanos e entende que estas podem estar presentes de modo inconsciente no indivíduo, que pode estar com menos saúde do que poderia e deveria estar. Para chegar ao ponto de se vivenciar efetivamente a EA, a humanidade, ou seja, o sistema das relações ecológicas, precisa incorporar transformações nas ações de preservação ambiental.

Urge "buscar uma perspectiva holística de ação, que relaciona o homem, a natureza e o universo, tendo em conta que os recursos naturais se esgotam e que o principal responsável pela sua degradação é o homem" (JACOBI, 2003, p. 196). Isso vem de encontro à resposta da pergunta 8, sobre as EE voltadas à EA durante o ano: "Aulas práticas, viagens de estudos, jogos didáticos, filmes e vídeos que enfocam diferentes temas em torno da EA" (P1). "Fazemos pesquisas, debates e observações do ambiente, sempre buscando práticas que melhorem nossas atitudes e o planeta em que vivemos" (P6). Quanto à pergunta 7, que se refere às EE de EA desenvolvidas em contexto escolar, a maioria respondeu que algumas delas seriam coleta seletiva do lixo, composteira, reutilização de óleo de cozinha para fazer sabão, conservação de energia, plantio de árvores, bem como desenvolver a sensibilidade com relação às questões ambientais. 
Entendemos que a EA tem relação com a vida estabelecida pelas pessoas no cotidiano, articulação esta que observamos indiretamente nas respostas da pergunta 7. Identificamos a EA como um tema que precisa atingir mais pessoas para que se aumente o entendimento da poluição da água, da questão do lixo e do saneamento básico, por exemplo, aspectos estes que atingem diretamente o ser humano. Nesse sentido, educar diz respeito à transformação da realidade por meio da modificação do comportamento, o que é acompanhado por novos conhecimentos dos educandos (GRETER; ARAÚJO, 2016).

Partindo de tais considerações, compreendemos que os professores fazem uso de diferentes EE emergentes, em sua maioria, do contexto vivenciado. A contemplação da EA nas escolas e nos cursos de formação de professores é concebida como possibilidade de formar um conhecimento capaz de articular teoria e prática, e de integrar escola, universidade e sociedade (TRISTÃO, 2004). A formação também tem como base a reflexão dos sujeitos sobre sua prática docente, de modo a permitir que examinem suas teorias implícitas, realizando um processo constante de autoavaliação para orientar o trabalho (IMBERNÓN, 2011).

É necessário avançar no sentido de mover ações desenvolvidas de EA para discussão e reflexão da importância da sistematização, pois esta decorre de um pensar crítico da docência, já que "aos estudantes importa ter uma visão ampla e diversificada da questão ambiental, para que conheçam melhor a ecologia local, regional e planetária" (UHMANN, 2013, p. 170). Esse movimento de pensar a docência com foco na EA torna as práticas capazes de articular mudanças frente aos problemas das questões socioambientais. A sistematização e o questionamento reconstrutivo contribuem (DEMO, 2005) para o desenvolvimento das práticas educativas, constituindo possíveis caminhos para a formação de sujeitos críticos capazes de criar, inventar e transformar as realidades vividas para melhor.

Elencamos a pergunta 10 com esse propósito em mente: “como são sistematizadas (avaliadas) as práticas de EA? Descreva algumas. Ainda, comente se elas acontecem de forma sistemática". P2 responde: "através de nota ou conceito" (lembrando que, para a questão 8, P2 respondeu: "estudo dos biomas e energia"). Entendemos com essa resposta que a sistematização é centrada na nota ou no conceito, vistos como produto final das ações de EA desenvolvidas - o que nos faz pensar que a proposta da inserção da EA tem amplitude maior, e, para tanto, o trabalho com projetos integradores e/ou inovadores tem mais potencial para efetivar as estratégias de sistematização contínuas da EA, a exemplo do trabalho citado no Quadro 6.

É necessário compreender a importância da sistematização das EE considerando-se a constante investigação da prática que se desenvolve, o que possibilita repensar o processo de ensino. É fundamental que o professor mova suas ações repensando a melhoria da prática no processo desenvolvido, longe de atribuir apenas uma nota/conceito ao aluno após a realização de uma prática. É interessante "quando os professores das escolas em viagens de campo participam ativamente da instrução no local junto com os instrutores de educação ambiental, assim os resultados dos alunos geralmente são mais positivos" (STERN; POWWER; HILL, 2014, p. 9, tradução nossa).

P7, ao responder à questão 10 , compreende a sistematização no sentido de "colocar em prática as ações estudadas" de EA (levando em conta que sua resposta para a questão 8 foi: "pesquisa e estudo de textos atuais"). "Educar é emancipar a humanidade, criar estados de liberdade diante das condições que nos colocamos no processo histórico e propiciar alternativas para irmos além de tais condições" (LOUREIRO, 2006, p. 32). Nesse sentido, compreendemos a ideia de P7; no entanto, sistematizar a ação desenvolvida, ou seja, pensar se determinada ação de EA foi significativa, requer a vigilância do professor em relação às ações com os alunos, lembrando que a ação pode ser pontual junto com o pensamento global. 
Contribuir com a educação planetária é superar os limites de seu descaso, pois "em eventos de EA, um observador mais atento verifica com facilidade o quanto há de pouca ênfase na problematização do que é realizado e na socialização de questionamentos acerca das experiências governamentais e não governamentais" (LOUREIRO, 2006, p. 22). Essa observação cabe às universidades e às escolas no que concerne à responsabilidade com que tratamos a questão socioambiental, ou seja: não podemos aceitar que essa problemática passe despercebida da nossa atuação docente.

No entanto isso ainda é frequente, tendo em vista a resposta dada à questão 10: "penso que ainda não fizemos uma avaliação sistemática das práticas que realizamos em sala de aula" (P1). Compreendemos, assim, o quanto a preocupação com a sistematização das ações da EA é pouco presente na docência, bem como em outros espaços que também geram aprendizagens. Isso ocasiona um processo de ensino linear e fragmentado, sem a devida integralização das questões sociais, ambientais e culturais. P1, ao responder à questão 8, diz que se vale de diferentes modalidades didáticas, como as "aulas práticas, viagens de estudos, jogos didáticos, filmes e vídeos que enfocam diferentes temas em torno da EA" (já apresentadas neste trabalho), mas tem dificuldade para avaliar de forma integral as ações desenvolvidas, tendo em vista que ainda não a realizou a discussão de nenhum filme, por exemplo, o que nos faz pensar que as concepções estão desconectadas da prática, ou então que as ações são estanques e têm pouca relação com os conceitos escolares.

Em geral, a falta de relação dos conceitos escolares com a EA é uma questão que permeia a vida escolar. Nesse sentido, percebemos a existência de problemas no que diz respeito ao planejamento, à realização e à sistematização de práticas efetivas da EA que precisam ser superadas. Assim, diríamos ainda "que a participação do professor na instrução no local desenvolve melhor os próprios significados da experiência, o que permite reforçar a aprendizagem do aluno durante e após a experiência" (STERN; POWWER; HILL, 2014, p. 9, tradução nossa), com foco na EA.

Torna-se de suma importância investigar com afinco "quais as dificuldades encontradas para trabalhar com a EA em sala de aula?" (pergunta 11). P3 responde: "turmas muito grandes, falta de respeito". Já P3 atribui a dificuldade de trabalhar a EA ao espaço e ao número de alunos, não mencionando ações diretas, por exemplo, com o acompanhamento de trilhas ecológicas, representações em desenho, jogos didáticos, estudo da história da EA, uso de multimídias, entre outras. Nesse sentido, reforçamos a importância de estudar as EE e a sistematização, com vistas a auxiliar o movimento de ensino e aprendizagem em espaços mais diversificados com foco na EA.

P1 descreve o cenário atual com preocupação: "é difícil sensibilizar os jovens que são muito influenciados pelo apelo de consumo da sociedade em que vivemos" (resposta à questão 11). O consumo induzido é uma questão importante a ser discutida, de maneira crítica. Um sujeito ecológico preocupado com o ambiente busca nas ações individuais e coletivas a sensibilização com a questão ambiental. P1 aponta o problema do consumo desenfreado, algo a ser pensado em todos os aspectos das relações políticas, econômicas e culturais.

Outro aspecto para o qual precisamos dar atenção são os meios de produção que visam diretamente o consumo. De acordo com Tristão (2004), essa dimensão, da qual tratamos, gera contradição entre desenvolvimento e qualidade de vida, compatíveis com nutrição, saúde e bem-estar da população. O autor aponta a exclusão social no Brasil como um grave problema, mas destaca que, independentemente de raça, etnia, cultura ou classe social, as consequências dos problemas ambientais atingem a todos, mesmo nos países com carência de tecnologia.

Desta forma, não teremos resposta para a crise se não começarmos a mudar nas esferas política, social e cultural, reorientando os objetivos dos modos/meios de produção de bens materiais (GUATTARI, 2012). Reforçamos o papel da escola como principal entidade que 
visa o entendimento e as transformações relativas às questões ambientais, pois "a EA necessita constituir-se num processo efetivo de desenvolvimento humano e social, principalmente, na escola" (UHMANN, 2013, p. 155).

Ainda sobre a pergunta 11, P2 responde: "nenhuma", ou seja, diz que não tem dificuldade de trabalhar a EA na sala de aula. P2 tinha como resposta para a questão 8: "estudo de biomas e energia"; e para a questão 10: "através de nota ou conceito". Evidenciamos a perspectiva de P2 sobre a questão da EA, que é tratada de forma simplificada no desenvolvimento dos conhecimentos sobre tais conceitos, sem especificar necessariamente como a relação é feita com a EA. Essa abordagem é tratada por Loureiro (2006), que destaca que educar exige responsabilidade social, com a devida problematização da realidade, e requer não se acomodar na posição conservadora de produtor e transmissor de conhecimentos, sem o entendimento preciso de que estes são mediados social e culturalmente de forma complexa.

Em decorrência das observações realizadas, evidenciamos a necessidade de avançar no campo crítico da formação inicial e continuada de professores com foco na EA. Outra observação está no fato de o trabalho docente individual passar a integrar o trabalho coletivo; para tanto, o planejamento de projetos ou de situação de estudo (SE) tem tido resultados favoráveis no desenvolvimento das ações escolares. Conforme Maldaner e Zanon (2004, p. 58), as SE se constituem como uma proposta de reorganização curricular diferenciada, ao "contemplar essa complexidade que é o trabalho pedagógico escolar. Pelo fato de partir da vivência social dos alunos, ela facilita a interação pedagógica necessária à construção da forma interdisciplinar de pensamento e à produção da aprendizagem significativa".

Enfim, o desafio consiste em socializar e estudar as EE com foco na EA, bem como na sistematização destas, visto que os participantes da pesquisa vêm desenvolvendo atividades voltadas às questões socioambientais. Esse processo de sistematização possibilita ações de EA condizentes com as mudanças necessárias, principalmente em contexto escolar. Assim, passamos às considerações finais, que tratam de ponderações relevantes para este estudo da temática ambiental.

\section{Considerações finais}

Com base neste estudo investigativo sobre a sistematização das EE com foco na EA foi possível evidenciar, a partir dos resultados obtidos, certa carência quanto ao entendimento da EA no contexto educacional, ainda pouco explorada pelos professores. A problematização as práticas de EA decorre da necessidade de que estas sejam introduzidas no cotidiano escolar, na perspectiva da adoção de hábitos mais saudáveis. Compreendemos que a sistematização das EE com foco na EA ainda é um desafio que precisa avançar, a começar pelo planejamento, pela ação e pela avaliação no coletivo escolar entre os professores, tendo em vista o cuidado da própria ação docente. Com base em Holliday (2006), compreendemos a sistematização como atividade de produção de conhecimento a partir da prática, confrontando o conhecimento teórico existente e contribuindo para convertê-lo em ferramenta para conhecer e transformar a realidade.

Enfocamos a discussão sobre as EE vinculadas à temática ambiental devido à importância de se compreender de que forma evoluíram as discussões no contexto escolar, em sala de aula, e se a atividade desenvolvida é pontual, específica ou se parte do contexto local e perpassa pelas relações globais. Perspectivas apontaram que, na maioria das vezes, as ações de EA continuam fragmentadas, sem a compreensão do todo junto com os alunos.

A partir da organização das seis temáticas aqui abordadas, foi possível destacar a $E E$ com foco na EA, que se desmembrou na organização dos quadros, destacando a escrita e o 
desenho, por exemplo, bem como as demais formas de sistematização encontradas. A ausência de sistematização das ações de EA se apresenta como fator limitante, visto que um processo contínuo de sistematização é fator determinante para potencializar o trabalho da EA em contexto escolar.

Nos impulsiona a necessidade de trabalhar com projetos e/ou com SE, inserindo a EA de forma transversal no ensino, de modo que os sujeitos escolares tenham a responsabilidade de trabalhar de forma coletiva, não se esquecendo das ações individuais, ou seja, no desenvolvimento das aulas e, por vezes, no coletivo escolar. Articular a EA no ensino dos conceitos escolares realmente é fator limitante atualmente; no entanto é preciso investir em ações articuladoras capazes de enfrentar as dificuldades no processo de mudança para uma melhor qualidade de vida no contexto educativo. É necessário pensar a EA e em quais de seus conceitos são imprescindíveis ao trabalho pedagógico em sala de aula, em que o profissional da educação vai além das informações e da apresentação de conceitos científicos.

"A Educação Ambiental Crítica volta-se para uma ação reflexiva de intervenção em uma realidade complexa; é coletiva; seu conteúdo encontra-se além dos livros, está na realidade socioambiental derrubando os muros da escola" (SANTOS et al, 2010, p. 142), com potencial para compreender e planejar atividades que perpassam pela EA, transformando-se em prioridade na formação de professores (que deve ser contínua), bem como no ensino. Destacamos que não existe um método ou receita: cabe ao professor planejar e viabilizar a melhor EE, na riqueza de desenvolver ações de EA adequadas a seu contexto.

Ao finalizarmos a escrita deste artigo - mas não a discussão acerca da EA -, chamamos atenção para a importância de mantermos uma postura crítica e investigativa, aberta ao diálogo, movendo assim o re(pensar) da prática constantemente.

\section{Referências}

AGUIAR, W. J.; FARIAS, C. R. O. Apontamentos para práticas de avaliação na educação ambiental em diálogo com saberes de professores da educação básica. Pesquisa em Educação Ambiental, Rio Claro, v. 12, n. 1, p. 10-25, jan. 2017. Disponível em: 〈https://bit.ly/2PirjY4>. Acesso em: 12 jan. 2018.

ALBERNAZ, R. M.; LAURINO, D. Formação ecosófica: tramas entre a formação e a educação ambiental. Revista Eletrônica do Mestrado em Educação Ambiental, Rio Grande, v. 27, p. 34-45, jul./dez. 2011. Disponível em: < https://bit.ly/2ApoI6v>. Acesso em: 12 jan. 2017.

BARCELOS, V. Navegando e traçando mapas: uma contribuição à pesquisa em educação ambiental. In: GALIAZZI, M. C.; FREITAS, J. V. Metodologias emergentes de pesquisa em educação ambiental. Ijuí: Unijuí, 2005. p. 63-84.

BARDIN, L. Análise de conteúdo. Lisboa: Edições 70, 1995.

DEMO, P. Educar pela pesquisa. 7. ed. Campinas: Autores Associados, 2005.

DIAS, G. F. Educação ambiental: princípios e práticas. 6. ed. São Paulo: Gaia, 2000.

DUARTE, M. L. A. S.; GUIMARÃES, H. R. C.; SILVA, M. M. P. Trabalhando educação ambiental através da arte na terceira idade. Revista Eletrônica do Mestrado em Educação Ambiental, Rio Grande, v. 25, n. 1, p. 133-147, jul./dez. 2010. Disponível em: 〈https://bit.ly/2PTacsK〉. Acesso em: 12 jan. 2017. 
FREIRE, P. Pedagogia da autonomia: saberes necessários à prática educativa. São Paulo: Paz e Terra, 1996.

GOLDBERG, L. G.; YUNES, M. A. M.; FREITAS, J. V. O desenho infantil na ótica da ecologia do desenvolvimento humano. Psicologia em Estudo, Maringá, v. 10, n. 1, p. 97-106, jan./abr. 2005. Disponível em: 〈https://bit.ly/2SdSIJc〉. Acesso em: 12 jan. 2017.

GRETER, T. C. P.; ARAÚJO, M. C. P. A compreensão de educação em saúde, para saúde e na saúde na formação docente e no contexto escolar. Revista da Associação Brasileira de Ensino de Biologia, Niterói, RJ, v. 9, p. 1205-1214 2016. Disponível em: <http://sbenbio.org.br/wpcontent/uploads/edicoes/revista_sbenbio_n9.pdf . Acesso em: 07 nov. 2018.

GUATTARI, F. As três ecologias. 21. ed. Campinas: Papirus, 2012.

HENNING, C. C.; GARRÉ, B. H.; HENNING, P. C. Discursos da educação ambiental na mídia: uma estratégia de controle social em operação. Revista Eletrônica do Mestrado em Educação Ambiental, Rio Grande, v. 25, p. 243-252, jul./dez. 2010. Disponível em: <https://bit.ly/2CCygfM>. Acesso em: 12 jan. 2017.

HOLliDAY, O. J. Para sistematizar experiências. Tradução Maria Viviana Rezende. 2. ed. Brasília, DF: Ministério do Meio Ambiente, 2006. Disponível em: <https://bit.ly/2JfFxmW>.Acesso em: 20 maio 2017.

IMBERNÓN, F. Formação docente e profissional: formar-se para a mudança e a incerteza. 9. ed. São Paulo: Cortez, 2011.

JACOBI, P. Educação ambiental, cidadania e sustentabilidade. Cadernos de Pesquisa, São Paulo, n. 118, p. 189-205, mar. 2003. Disponível em: 〈https://bit.ly/1L2SPwI>. Acesso em: 20 maio 2017.

LEFF, E. Racionalidade ambiental: a reapropriação social da natureza. Rio de Janeiro: Civilização Brasileira, 2006.

LOUREIRO, C. F. B. Trajetória e fundamentos da educação ambiental. 2. ed. São Paulo: Cortez, 2006.

LÜDKE, M.; ANDRÉ, M. E. D. A. Pesquisa em educação: abordagens qualitativas. 2. ed. Rio de Janeiro: E.P.U., 2013.

MALDANER, O. A.; ZANON, L. B. Situação de estudo: uma organização do ensino que extrapola a formação disciplinar em ciências. In: MORAES, R.; MANCUSO, R. (org.). Educação em ciências: produção de currículos e formação de professores. Ijuí: Unijuí, 2004. p. 43-64.

MARQUES, M. O. Educação nas ciências: interlocução e complementaridade. Ijuí: Unijuí, 2002.

METTE, G.; SILVA, J. C. D.; TOMIO, D. Trilhas interpretativas na mata atlântica: uma proposta para educação ambiental na escola. Revista Eletrônica do Mestrado em Educação Ambiental, Rio Grande, v. 25, p. 111-122, jul. 2010. Disponível em: 〈https://bit.ly/2q8YbEo>. Acesso em: 12 jan. 2017. 
SANTOS, W. L. P. et al. O enfoque CTS e a educação ambiental: possibilidade de "ambientalização" da sala de aula de ciências. In: SANTOS, W. L. P.; MALDANER, O. A. (org.). Ensino de química em foco. Ijuí: Unijuí, 2010. p. 28-31

SANTOS, W. L. P.; SCHNETZLER, R. P. Educação em química, compromisso com a cidadania. 3. ed. Ijuí: Unijuí, 2003.

SILVA, N. B.; JÚNIOR, M. F. S. Educação ambiental e práticas pedagógicas comunicativas no ensino fundamental do CAIC em Vitória da Conquista - BA. Revista Eletrônica do Mestrado em Educação Ambiental, Rio Grande, v. 29, p. 1-14, jul./dez. 2012. Disponível em: 〈https://bit.ly/2z3Qcwj〉. Acesso em: 12 jan. 2017.

STERN, M. J; POWWER, R. B; HILL, D. Environmental education program evaluation in the new millennium: what do we measure and what have we learned? Environmental Education Research, Abingdon, v. 20, n. 5, p. 581-611, 2014. Disponível em: 〈https://bit.ly/2ShCjDz>. Acesso em: 5 set. 2018.

STRIEDER, R. Educação ambiental versus natureza humana: do Homo rapiens ao Homo sapiens. Revista Eletrônica do Mestrado em Educação Ambiental, Rio Grande, v. 28, p. 189-204, jan./jun. 2012. Disponível em: <https://bit.ly/2PoYFoo>. Acesso em: 12 jan. 2017.

TRISTÃO, M. A educação ambiental na formação de professores: redes de saberes. São Paulo: Annablume, 2004.

UHMANN, R. I. M. Interações e estratégias de ensino de ciências com foco na educação ambiental. Curitiba: Appris, 2013.

WENZEL, J. S. A escrita em processos interativos: (re)significando conceitos e a prática pedagógica em aulas de Química. Curitiba: Appris, 2014. 